\title{
The relation between social rank, neophobia and individual learning in starlings
}

\author{
NEELTJE J. BOOGERT*, SIMON M. READER* \& KEVIN N. LALAND† \\ *Behavioural Biology and Helmholtz Institute, Utrecht University \\ $\dagger$ School of Biology, University of St Andrews \\ (Received 27 July 2005; initial acceptance 7 September 2005; \\ final acceptance 24 February 2006; published online 2 October 2006; MS. number: 8634R)
}

\begin{abstract}
Researchers with diverse interests in topics ranging from the formation of dominance hierarchies and social intelligence to animal personalities have predicted specific, and often conflicting, relations between social rank, neophobia and learning ability. We investigated the relations between these variables in captive groups of wild-caught starlings, Sturnus vulgaris, adopting a multidimensional approach to social rank and neophobia. Both agonistic and competitive rank orders were determined for each group and we tested individuals in the absence of their groupmates for object neophobia, latency to feed in a novel environment and performance on an extractive foraging task. In each starling group, the fastest learners occupied the highest competitive ranks, supporting the hypothesis that cognitive ability is positively correlated with social dominance. Competitive rank orders, however, did not correlate significantly with agonistic rank orders. Situation-specific foraging neophobia was suggested: individuals showed consistency in their latencies to feed near a variety of novel objects, but no significant correlation was found between this measure of object neophobia and latency to feed in a novel environment. Starlings fastest to feed in the novel environment were fastest in solving the foraging task. We discuss the implications of these findings for researchers studying hierarchy formation in animal groups, social intelligence and animal personalities.
\end{abstract}

(c) 2006 The Association for the Study of Animal Behaviour. Published by Elsevier Ltd. All rights reserved.

In gregarious species, social relationships often take the form of dominance hierarchies in which individuals can be characterized by a social rank (Chase 1980). These social rank orders have been found to correlate with other behavioural variables such as reactions to novelty and learning performance. However, a variety of relations between social rank, learning performance and novelty responses have been predicted, and different predictions are made according to whether individuals are within or outside their social group. These relations are further complicated by the fact that rank orders can be measured in different ways (e.g. agonistic and competitive rank) that do not necessarily correspond with each other (Syme 1974). Furthermore, while acquisition of dominance status may influence learning performance (Bunnell \&

Correspondence and present address: N. J. Boogert, Department of Biology, McGill University, 1205 avenue Docteur Penfield, Montréal, Québec H3A 1B1, Canada (email: njboogert@gmail.com). S. M. Reader is at Behavioural Biology, Utrecht University, Padualaan 8, P.O. Box 80086, 3508 TB Utrecht, The Netherlands. K. N. Laland is at the Centre for Social Learning and Cognitive Evolution, School of Biology, University of St Andrews, Bute Medical Building, Queen's Terrace, St Andrews, Fife KY16 9TS, U.K.
Perkins 1980; Barnard \& Luo 2002), 'social intelligence' hypotheses view learning performance as a determinant of social success (Humphrey 1976).

Within a social group, dominant individuals are likely to limit subordinates' access to preferred resources. Thus group members' motivation levels may differ even if their capacities or propensities are similar, and this may be reflected in their learning performance or responses to novelty. For example, mid- to low-ranking individuals are quicker to detect and enter novel locations, and so are less neophobic, than dominant groupmates in birds (jackdaws, Corvus monedula: Katzir 1982; barnacle geese, Branta leucopsis: Stahl et al. 2001) and capuchin monkeys, Cebus apella (di Bitetti \& Janson 2001). Thus subordinate individuals may be forced, by their lack of access to established resources, to incur the potential costs and risks of exploration (Laland \& Reader 1999), whereas dominants can subsequently displace subordinates if and when the latter locate valuable resources. According to this scenario, low-ranking individuals would not necessarily be predicted to be less neophobic (or more neophilic) than high-rankers when away from the group, since it is the social context that evokes rank-dependent responses to novelty. 
Similarly, learning performance in a group context may be affected by social rank. Dominant rhesus macaques, Macaca mulatta, for example, appear to show superior learning capacities to subordinates when tested within the group, but when dominants and subordinates are separated their learning performance is similar (Drea \& Wallen 1999). Being low in a dominance hierarchy may force individuals to deviate from their usual behaviour, for instance to relinquish access to resources, or conversely to learn novel acts to obtain resources, as reported in a variety of primate and avian species (e.g. Cambefort 1981; Kummer \& Goodall 1985; Reader \& Laland 2001, 2003; Bugnyar \& Kotrschal 2004). Individual performance measured during temporary separation from the group may thus be informative in interpreting group level performance. Although there may be carryovers from the group to the isolated context (e.g. carryovers of motivational state or of learned strategies reinforced while in the group), testing of separated individuals allows assessment of the influence of other group members and may reduce their immediate influence on the subjects' performance.

The 'prior attributes' hypothesis views rank order as resulting from individual differences existing before group formation (Chase et al. 2002). Learning propensity could be one such attribute that determines social rank. Humphrey (1976), in his discussion of the social function of intellect, proposed that individuals of superior cognitive ability will be more successful socially. Intelligent individuals may rise in social rank because they outcompete cognitively inferior groupmates. Acquisition of high rank, and thus access to desired resources, may remove the need to perform some learned behaviour. However, when tested in isolation, high-rankers would still be expected to outperform groupmates on relevant cognitive tasks. The abilities to learn about social relationships, to innovate in the social domain and to deceive others have been proposed as important cognitive determinants of social success, but cognitive superiority may extend to, or correlate with, learning performance in general (Humphrey 1976; Byrne \& Whiten 1988; Seyfarth \& Cheney 2002). While social intelligence hypotheses have received a great deal of attention as explanations for interspecific differences in brain and cognition (e.g. Templeton et al. 1999; Reader \& Laland 2002; Dunbar 2003), within-group relations between social rank and learning performance have received less scientific scrutiny. Consistent with social intelligence ideas, Nicol \& Pope (1999) found that socially dominant hens, Gallus gallus domesticus, tested away from their group perform better on one measure of social learning than subordinate hens.

Correlations between social rank and individual learning performance may be a consequence of differing learning propensities (i.e. prior attributes), but may also arise because changes in rank influence learning performance. Barnard \& Luo (2002) reported that, after laboratory mice, Mus musculus, were paired and agonistic rank within the pair determined, dominants tested in isolation showed more correct responses on a radial maze task than subordinates in the early test trials, whereas before pairing there were no significant performance differences within pairs. In contrast, lower-ranking longtailed macaques, Macaca fascicularis, are the best learners when tested in isolation (Bunnell \& Perkins 1980; Bunnell et al. 1980), and drops in relative rank are associated with improvements in performance. Alternatively, rank and learning may not be causally related but, instead, might correlate with a third variable, such as reaction to novelty.

We sought to clarify the relations between learning performance, novelty responses and rank by directly assessing the associations between social rank in a group, and reactions to novelty and individual learning performance in the absence of groupmates, in individuals of a gregarious species. We hypothesized that (1) high social rank correlates positively with individual learning performance tested in isolation, whereas (2) there is no relation between social rank and neophobia tested in isolation. Although empirical assessment of these hypotheses may seem straightforward, caution is warranted as both social rank and reaction to novelty may be measured in different ways, with significant consequences for the relations found between these and other variables (Syme 1974; Coleman \& Wilson 1998). Social rank can be determined by recording (1) the outcome of agonistic encounters or (2) priority of access to limited resources (e.g. King 1965; Richards 1974; Syme et al. 1974; Chase 1982; Tebbich et al. 1996; Vervaecke et al. 1999, 2000; Barnard \& Luo 2002). However, the agonistic rank order of a group may differ from its competitive rank order (Syme 1974).

We therefore investigated the relations between social rank, reaction to novelty and individual learning performance by (1) determining both agonistic and competitive rank orders in the group, followed by (2) a series of tests of isolated individuals' responses to both novel space and novel objects, and (3) assessment of their individual learning performance. Although our design does not allow us to identify the causal variable behind a correlation between social rank and individual behaviour, the abovementioned relations have never been assessed together in a single gregarious species from the wild. Thus this preliminary exercise is required to improve understanding of the links between cognition, neophobia and social structure.

We tested our hypotheses in captive groups of European starlings, Sturnus vulgaris. Starlings are highly gregarious birds that feed in flocks and congregate in day and night roosts (Feare 1984). After arrival at the night roost, birds frequently supplant each other, leading to a definite social structure that is thought to reflect dominance (Summers et al. 1987). In captive starlings, social rank correlates with various physical traits. High agonistic rank correlates negatively with increases in body mass during reproductive development (Witter \& Goldsmith 1997), whereas dominance correlates positively with both primary feather asymmetry and chest plumage spottiness (Swaddle \& Witter 1994, 1995; Witter \& Swaddle 1994). In addition, numerous studies have shown starlings to be capable of learning to solve foraging tasks in the laboratory (e.g. Bateson \& Kacelnik 1995; Templeton \& Giraldeau 1995; Templeton 1998; Campbell et al. 1999; Fawcett et al. 2002; Kacelnik \& Marsh 2002). However, the relations between dominance and behavioural variables such as 
reaction to novelty and individual learning performance remain to be determined. These may be important as starlings have an opportunistic lifestyle, showing flexibility in mating systems and in the exploitation of available food supplies (Feare 1984).

\section{METHODS}

\section{Subjects and Apparatus}

Fifteen wild male starlings were caught in the surroundings of St Andrews, U.K., with baited walk-in traps, ringed and divided at random into three groups of five individuals each. The trapping method is unlikely to provide a random sample of birds, but our comparisons are made within this sample. The groups were housed in adjacent wire-mesh cages $(126 \times 108 \mathrm{~cm}$ and $176 \mathrm{~cm}$ high), bedded with corncob granules and enriched with tree branches, perches and a bird house. Water and softened dog food crumbs were available ad libitum unless stated otherwise. Light was provided by full-spectrum fluorescent light tubes $(65 \mathrm{~W})$. The birds were maintained on a 14:10 h light:dark cycle (light onset 0700 hours), at a temperature of $19-20^{\circ} \mathrm{C}$. The starlings had been in captivity in the same groups for 7-10 months before the experiments and were experimentally naive. We assume that in this period the birds habituated to laboratory life and that the dominance hierarchies in their groups had become stable. We cannot control for previous experience in the wild. To reduce effects of the observer on the test subjects (Martin \& Bateson 1993; Lehner 1996; Witter \& Goldsmith 1997), we made all observations from a cardboard hide with a small peep hole, from a distance of approximately $50 \mathrm{~cm}$.

Priority of access to buried mealworms was assessed with a small opaque cup (diameter $7.3 \mathrm{~cm}$, height $4 \mathrm{~cm}$ ) filled with 15 mealworms (larvae of the beetle Tenebrio molitor) that were halved to increase the number of items and hidden in gravel. Under natural circumstances, starlings probe the soil for invertebrates (Feare 1984) and mealworms represent a highly desirable food source. The same cup had been presented numerous times, with food, before data collection.

To assess priority of access both to mealworms presented on top of the normal food in the group dish and to water, we used plastic brown flowerpot saucers (diameter $21 \mathrm{~cm}$, height $4.8 \mathrm{~cm}$ ) as the food and water dishes.

The novel objects used to test for object neophobia were (1) an assemblage of five differently coloured clothes pins $(2.7 \times 9 \mathrm{~cm} /$ pin $),(2)$ Styrofoam packing material mounted on a cardboard plate $(9 \times 9 \mathrm{~cm})$, (3) a band of yellow reflective material $(3 \times 3.1 \times 11 \mathrm{~cm})$, $(4)$ a white opaque laboratory tube cap (diameter $2 \mathrm{~cm}$, height $1.6 \mathrm{~cm}$ ), (5) a white spool of light purple elastic wire (diameter $1.7 \mathrm{~cm}$, height $6.5 \mathrm{~cm}$ ) and (6) a bright green opaque pen cap (diameter $1 \mathrm{~cm}$, height $2.5 \mathrm{~cm}$ ).

The individual learning task consisted of a food dish (a plastic brown flowerpot saucer (diameter $7.9 \mathrm{~cm}$, height $2 \mathrm{~cm})$ taped to a wooden plate $(8 \times 11.5$ and $0.5 \mathrm{~cm}$ high), to prevent it being overturned) covered with an upside-down transparent petri dish lid (diameter $8.8 \mathrm{~cm}$, height $1.5 \mathrm{~cm}$ ) that the bird had to peck off to reach the mealworm underneath. Green garden wire held the lid in place to prevent accidental removal by claws or wings, thus ensuring that the task could be solved only by pecking horizontally at the side of the lid.

\section{Procedure}

One day before the start of the experiments, the starling group to be studied was transferred to a cage in an experimental room identical to that in the housing room, but isolated from other birds. After completion of an experiment (i.e. data collection on social rank orders on days 1-5 and individual tests over days 14-21), the studied group was returned to the housing room and the same experiment was conducted with each of the other groups in turn.

\section{Social Rank Orders}

All measures on social rank orders were taken per group over 5 consecutive days.

\section{Agonistic rank order}

Each starling group was observed daily at approximately 0800-0900, 1600-1630 and 1800-1900 hours. We noted identities of birds showing agonistic behaviour in the form of displacements, pecking, tugging of tail feathers and threatening, as well as the recipients of this behaviour and their reactions (i.e. flight, submissive crouching, shrieking). When an aggressive act was ignored or not followed by submission of the target individual, the event was not recorded so that only supposedly mutually acknowledged agonistic interactions were used in analyses (Vervaecke et al. 2000).

\section{Competitive rank order}

Priority of access to buried mealworms presented in a small opaque cup. Each starling group was deprived of food twice daily at 0800 and 1400 hours for $1 \mathrm{~h}$. After food deprivation, the group was presented with a white opaque cup filled with 15 halved mealworms hidden in gravel. The time that each bird monopolized the cup in search of mealworms was recorded for 10 10-min trials (two trials per day over 5 consecutive days).

Priority of access to mealworms presented in the normal food dish. Priority of access to mealworms presented in the opaque cup might have been confounded by individuals' wariness to approach this feeding situation. Therefore, we used an additional measure of priority of access to mealworms to substantiate previous findings. Once each day between 1600 and 1700 hours, the normal food dish was removed, 30 mealworm halves were sprinkled on top of the usual food and the dish was presented to the group. We recorded the order in which the birds started feeding and the relative number of mealworms eaten by each bird (i.e. most, many, some, few or none of the mealworms).

Priority of access to water. When presented with a dish of fresh water, starlings fought over priority of access to take a bath. After data collection on priority of access to 
mealworms in the small opaque cup, the normal water dish was refilled with fresh water and presented to the starling group. The time that each bird monopolized the water dish was recorded for 10 10-min trials (two trials per day over 5 consecutive days).

\section{Individual Variables}

Each bird was tested individually on (1) latency to feed in a novel environment, (2) control latency to feed, (3) object neophobia and (4) individual learning performance, in that order. Before each test, the test subject was transferred to another aviary in the experimental room where it was visually isolated from its group and deprived of food for $90 \mathrm{~min}$. This period of food deprivation is within the range of temporary unavailability of food experienced periodically by starlings in the wild (Fawcett et al. 2002). The test subject was placed back into its group each day after testing.

\section{Latency to feed in a novel environment}

The starling to be tested was transferred from its group cage to the visually isolated aviary. A Perspex sheet partitioned the test aviary lengthwise in two, and the subject was placed in the right half of the aviary $(126 \times 54 \mathrm{~cm}$ and $176 \mathrm{~cm}$ high). Thus, the individual found itself in a 'novel environment' socially (i.e. it was alone) as well as physically (i.e. it was in an unfamiliar aviary). After 90 min of food deprivation, the test subject received one mealworm in its usual food dish and we recorded its latency to feed. If the test subject did not feed within $10 \mathrm{~min}$, the dish was removed and presented again after a 2-min interval, up to nine trials per day for 4 consecutive days.

\section{Control latency to feed}

Upon its first feed in the novel environment, the test subject was presented repeatedly with the usual food dish containing one mealworm in daily blocks of three 10-min trials with 2-min intertrial intervals, until (i.e. after $N=1-8$ trials) latency to feed was observed to oscillate around a certain value. The mean of these oscillatory or 'equilibrium' values $(N=6-11$ trials) was defined as the control latency to feed and used in subsequent analyses.

\section{Object neophobia}

Each object neophobia test consisted of three 10-min trials with intertrial intervals of $2 \mathrm{~min}$. Trial numbers 1 and 3 of each test were used to control for feeding motivation: we presented the starling with its usual food dish containing one mealworm and recorded latency to feed. In trial number 2, the test subject received both its usual dish containing one mealworm and one of the novel objects (described above) placed $2 \mathrm{~cm}$ to the right of the dish. We recorded latency to feed near the novel object (Greenberg 1983, 1984). If a bird did not feed within $10 \mathrm{~min}$, it was assigned a ceiling value of $601 \mathrm{~s}$. Birds were tested on one novel object per day for up to six novel objects, depending on the number required to distinguish between individuals within groups such that they could be ranked. Thus, the number of novel objects presented to each individual was the same for all members of a group, but differed between groups. Within each group, initial order of birds tested was random but kept constant across days. Order of the novel objects presented was randomized across individuals (Webster \& Lefebvre 2001).

\section{Individual learning performance}

The test subject was presented with the learning task apparatus containing one mealworm and the petri dish lid placed next to it. The learning test was initiated only after the test subject fed within its control latency to feed from this 'opened' learning task apparatus. In this way, test subjects were habituated to the task apparatus before the test, thus minimizing interindividual differences in object neophobia to the task apparatus. The difficulty of the task varied across five levels. At level 1, a quarter of the dish was covered by the lid, half was covered at task level 2 , three-quarters at level 3, five-eighths at level 4 up to task level 5 where the dish was completely covered. We adopted a systematic shaping procedure that progressively led the subject through the levels of the task (Carlier \& Lefebvre 1996; Seferta et al. 2001). When the starling managed to reach and eat the mealworm on two subsequent trials, it passed on to the next level of difficulty on the next trial. Conversely, when a bird failed to eat on two subsequent trials at a given level, it returned to the previous level of difficulty. As a measure of individual learning performance, the trial number and latency at which each starling passed each task level were recorded, with a maximum of 70 10-min trials distributed over daily blocks of 10 10-min trials with 1-min intertrial intervals.

\section{Ethical Note}

Starlings were caught under a Scottish National Heritage Bird Scientific Licence. They were caught as juveniles in January and April 2004 with walk-in traps baited with lard containing a mixture of seeds. Within $15 \mathrm{~min}$ of capture the birds were transferred to the aviaries of the bird house at the University of St Andrews with water and food available ad libitum, and after the experiments were successfully released at their capture locations. Starlings maintained their weights and were generally in good health throughout the experiments, as certified monthly by the university vet and regularly by the local Home Office representative who approved all procedures. Agonistic physical interactions consisted of pecking and tugging of tail feathers, but were infrequent, always of very short duration and never caused any physical injury. The presence of dominant birds did not impede subordinates' access to the regular dog food and water dishes as these did not cause agonistic interactions outside the experimental context, being available continuously.

\section{Analyses}

\section{Agonistic rank order}

David's scores. David's scores use the outcomes of agonistic interactions between group members to calculate 
agonistic ranks, while taking the relative strengths of the opponents into account (Gammell et al. 2003): the proportion of wins by individual $i$ in his interactions with another individual $j\left(P_{i j}\right)$ is the number of times that $i$ defeats $j\left(\alpha_{i j}\right)$ divided by the total number of interactions between $i$ and $j\left(n_{i j}\right)$, thus $P_{i j}=\alpha_{i j} / n_{i j}$. The proportion of losses by $i$ in interactions with $j, P_{j i}=1-P_{i j}$. Subsequently, the David's score (DS) for each member, $i$, of a group is calculated with the formula DS $=w+w_{2}-l-l_{2}$, where $w=\sum P_{i j}$; $w_{2}=\sum w$, weighted by the appropriate $P_{i j}$ values, of those individuals with which $i$ interacted; $l=\sum P_{j i} ;$ and $l_{2}=\sum l$, weighted by the appropriate $P_{j i}$ values, of those individuals with which $i$ interacted (Gammell et al. 2003). A correction of $P_{i j}$, termed $d_{i j}$, should be used when interaction frequency varies substantially between dyads (de Vries 1998), as was the case in our study. However, de Vries et al. (2006) have recently developed a simpler correction to $P_{i j}$ and the latter was adopted here: $d_{i j}=\left(\alpha_{i j}+0.5\right) /\left(n_{i j}+1\right)$. David's scores were calculated for displacements, pecking, tugging of tail feathers and threats.

Directional Consistency index. According to Vervaecke et al. (2000), a behavioural variable should be a predominantly unidirectional interaction expressed in most dyads in the group to justify its use in a dominance model. Degree of unidirectionality can be calculated with the Directional Consistency index (DC; Vervaecke et al. 2000); the total number of times the behaviour occurred in the direction of the higher frequency $(H)$ minus the number of times in the less frequent direction $(L)$ is divided by the total frequency: $\mathrm{DC}=(H-L) /(H+L)$. This index varies between 0 (performance of behaviour completely bidirectional) and 1 (completely unidirectional; Vervaecke et al. 2000). DC was calculated for displacements, pecking, tugging of tail feathers and threats.

\section{Competitive rank order}

The time that each bird monopolized the opaque cup (test 1) and the water dish (test 3) was summed over the 10 10-min trials of each measure. Ranks were assigned accordingly, with the individual observed to monopolize the cup or dish the least occupying the lowest rank (rank 5). The bird that fed first and/or ate most of the mealworms presented in the normal food dish (test 2) was given rank 1 and so forth. Individuals not spending any time probing the cup's gravel, feeding on the mealworms in the normal food dish or bathing were assigned tied bottom ranks. A composite competitive rank order was determined by summing the individuals' relative ranks in each of tests 1, 2 and 3 .

\section{Social rank orders}

The association between competitive rank order measures $1-3$ and the relation between the agonistic and composite competitive rank orders were analysed with two-tailed Spearman correlation tests.

\section{Individual variables}

All feeding latencies were log-transformed to meet assumptions of normality and homogeneity of variance for subsequent parametric tests. Where these assumptions were not met, the transformed data were analysed with nonparametric tests. To correct for individual motivation and/or feeding speed, latency to feed first in a novel environment and latencies to feed next to each of the different novel objects were separately regressed against mean log-transformed control latency to feed. Residuals were taken and converted into $Z$ scores for each group (Lefebvre \& Giraldeau 1996).

\section{Object neophobia}

Feeding latencies in trials 1 and 3 were compared to feeding latencies in trial 2 across all objects and birds, to certify the validity of trial 2 as a measure of object neophobia. To this end we used a two-tailed nonparametric Wilcoxon signed-ranks test for two related samples. To test individuals' consistency in their responses to different novel objects we used two-tailed Pearson correlation tests. Subsequently, we computed for each bird the mean of the $Z$ scores of all object neophobia residuals, resulting in a single measure of object neophobia per individual.

\section{Individual learning performance}

As only eight of 15 birds (53\%) passed level 5 of the individual learning task, whereas 12 (80\%) passed level 4, we used the cumulative number of trials required to pass level 4 (with nonsolvers awarded a ceiling score of 70 trials) as a measure of individual learning performance in subsequent analyses, after natural log transformation and conversion into $Z$ scores for each group.

\section{Pooling data across groups}

When not significantly different, data from the three groups were pooled for subsequent analyses on the relations between individual variables. To compare groups for significant differences, we used the parametric oneway ANOVA when the transformed data of the three groups met the assumptions of normality and homogeneity of variance; the parametric independent-samples $t$ test was conducted when these assumptions were met but data were available for two groups only, and the nonparametric Kruskal-Wallis test was used to compare the three groups when the data, after transformation, remained not normally distributed. The relations between object neophobia, latency to feed in a novel environment and individual learning performance across the three starling groups were analysed with two-tailed Pearson correlation tests.

\section{Social rank orders versus individual variables}

The relations between agonistic and competitive rank orders versus individual variables were analysed per group with two-tailed Spearman rank correlations. We conducted a meta-analysis on the relation between competitive rank and individual learning performance, using Fisher's combination technique (Sokal \& Rohlf 1998). 


\section{RESULTS}

\section{Social Rank Orders}

To determine agonistic rank orders, we first evaluated which type of agonistic interaction was most suitable according to Vervaecke et al. (2000)'s criteria (see above). In each group, the bulk of agonistic interactions observed were displacements, followed by pecking and then the relatively rare tail feather tugging and threats (Table 1). Directional Consistency indexes (DC's) varied across types of agonistic interactions and between groups (Table 1). As displacements were by far the most frequently observed agonistic interactions and were performed with arguably sufficient unidirectionality, they were used to compute David's scores for determining agonistic rank orders.

The competitive rank order measures 1 and 2 correlated significantly with each other (Spearman rank correlation: $\left.r_{\mathrm{S}}=0.66, N=15, P=0.008\right)$ and these feeding data combined correlated with measure 3 on priority of access to water $\left(r_{\mathrm{S}}=0.59, N=15, P=0.02\right)$. However, no significant correlation was found between composite competitive rank orders based on these feeding/bathing data and agonistic rank orders based on displacements $\left(r_{\mathrm{S}}=-0.35, N=15, P=0.20\right.$; group $1: r_{\mathrm{S}}=-0.80, N=5$, $P=0.10 ;$ group $2: r_{\mathrm{S}}=0.10, N=5, P=0.87$; group 3 : $r_{\mathrm{S}}=-0.40, N=5, P=0.51 ;$ Fig. 1 ).

\section{Object Neophobia}

Across all objects and groups, both feeding latencies in trial 1 (i.e. before presentation of the novel objects) and feeding latencies in trial 3 (i.e. upon removal of the novel objects) were significantly shorter than latencies to feed near the novel objects (Wilcoxon signed-ranks tests: trial 1 versus trial 2: $Z=-6.89, N=65, P<0.001$; trial 3 versus trial 2: $Z=-6.89 ; N=65, P<0.001)$. Thus, the presence of novel objects slowed initiation of feeding significantly, justifying our usage of residual latency to feed near the novel objects as a measure of object neophobia.

Interindividual differences in object neophobia were apparent after birds had been tested on three novel objects

Table 1. Directional Consistency indexes (DC's) for each type of agonistic interaction for each group of starlings, and percentages of the total number of interactions, summed across groups, of the four types of agonistic interactions observed to determine agonistic rank orders

\begin{tabular}{|lccccc|}
\hline & \multicolumn{3}{c}{ Group } & \\
\cline { 2 - 4 } $\begin{array}{l}\text { Agonistic } \\
\text { interactions }\end{array}$ & & & & $\begin{array}{c}\text { \% All interactions } \\
(\bar{X} \pm S D, N=3)\end{array}$ \\
\hline Displacements & 0.42 & 0.78 & 0.80 & $58.3 \pm 4.75$ \\
Pecking & 0.37 & 0.70 & 0.39 & $31.6 \pm 3.12$ \\
Tugging of tail feathers & 0.73 & 0.79 & 0.77 & $5.1 \pm 2.09$ \\
Threats & 0.62 & 0.87 & NC & $3.1 \pm 2.06$ \\
\hline
\end{tabular}

NC: Not computed because of small sample size $(N=4)$.

${ }^{*} N=459 \pm 118$ observed in a mean \pm SD of $549 \pm 81$ min for three groups.

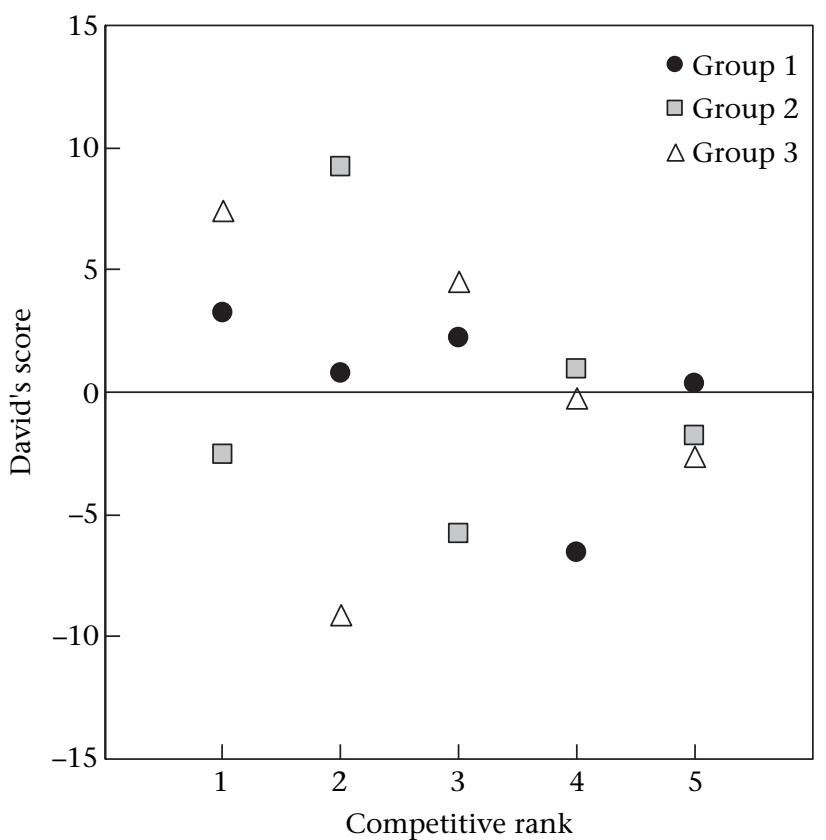

Figure 1. The relation between David's scores of displacements as a measure of agonistic dominance and competitive rank orders based on feeding/bathing data in starling groups 1, 2 and 3. Each datum represents one bird. High David's scores represent dominant individuals.

(Styrofoam objects, clothes pins and reflective band) in group 1, four novel objects (+ white tube cap) in group 2 and six novel objects $(+$ white tube cap + spool of wire + green opaque pen cap) in group 3 . We pooled the data per novel object across groups for subsequent analyses, since the three starling groups did not differ significantly in latency to feed near the same novel objects (one-way ANOVA log-transformed residual latency to feed near Styrofoam objects: $F_{2,12}=0.00, P=1.00$; Levene's test of homogeneity of variances: $F_{2,12}=1.43, P=0.28$; Kruskal-Wallis test log-transformed residual latency to feed near clothes pins: $\chi_{2}^{2}=0.26, P=0.88$; independentsamples $t$ test ( $N=2$ groups) log-transformed residual latency to feed near white tube cap: $t_{8}=0.00, P=1.00$; Levene's test for equality of variances: $F_{8}=2.75, P=0.14$ ).

Birds showed individual consistency in their responses to the different novel objects. The correlation between residual latencies to feed near Styrofoam objects and clothes pins was highly significant (Pearson correlation: $\left.r_{13}=0.88, P<0.001\right)$, as was the correlation between residual latencies to feed near Styrofoam objects and the white tube cap $\left(r_{8}=0.72, P=0.02\right)$ and clothes pins versus the white tube cap $\left(r_{8}=0.85, P=0.002\right)$.

\section{Latency to Feed in a Novel Environment}

Latency to feed in a novel environment did not differ significantly between groups (one-way ANOVA log-transformed residual latency to feed in a novel environment: $F_{2,12}=0.00, P=1.00$; Levene's test of homogeneity of variances: $\left.F_{2,12}=0.85, P=0.45\right)$. 


\section{Object Neophobia Versus Latency to Feed in a Novel Environment}

No significant relation was found between mean residual latency to feed near all novel objects (i.e. object neophobia) and residual latency to feed in a novel environment (Pearson correlation: $r_{13}=0.35, P=0.20$; power $=0.20$ when calculated with Cohen's (1988) medium effect size of $r=0.30$ and $\alpha=0.05$. Thus the statistical power of this test was low. The same effect size and $\alpha$ were assumed for the power analyses that follow).

\section{Individual Learning Performance}

Birds varied substantially in learning performance $(\bar{X} \pm \mathrm{SD}=32 \pm 26$ trials $)$. All birds interacted with the foraging task apparatus and passed level 1, and all but one individual solved the task at level 2 . Three birds passed level 4 within the smallest possible number of eight trials, whereas three other starlings were given a ceiling score of 70 trials. As the results across groups did not differ significantly from each other (one-way ANOVA log-transformed cumulative number of trials to pass level $4: F_{2,12}=0.86$, $P=0.45$; Levene's test of homogeneity of variances: $F_{2,12}=0.20, P=0.82$ ), data were pooled for subsequent analyses on associations between individual variables.

\section{Individual Learning Performance Versus Neophobia}

No significant relation was found between individual learning performance and object neophobia (Pearson correlation: $r_{13}=-0.01, P=0.97$; power $=0.20$ ), suggesting that individual differences in the learning test reflect variation in learning ability rather than in neophobia to the task. Learning performance did correlate significantly with latency to feed in a novel environment $\left(r_{13}=0.54\right.$, $P<0.05)$ : individuals quickest to feed in the novel environment required the fewest trials to pass level 4 of the individual learning task.

\section{Social Rank Orders Versus Individual Variables}

Correlations between social rank orders and individual variables differed between groups (Table 2). With the exception of the relation between competitive rank and latency to feed in a novel environment in group 3, none of these correlations remained significant when $\alpha$ was adjusted to control for familywise error rate $\left(\alpha^{*}=\alpha /\right.$ no. of tests conducted per variable $=0.05 / 3=0.017$; Table 2 ). A sequential Bonferroni technique (Rice 1989) gave the same finding. Only one relation between social ranks and individual variables was consistent across the three groups: a positive association was found between competitive rank orders and individual learning performance. Individuals occupying the highest competitive ranks (i.e. the dominants) required the fewest trials to pass level 4 of the individual learning task (Fig. 2). The strength and consistency of this relation justifies combining the $P$ values of the three groups with Fisher's technique (Sokal \& Rohlf 1998), resulting in $\chi_{6}^{2}=19.78$ with $P<0.005$.

\section{DISCUSSION}

Our most interesting finding regarding the relations between dominance, neophobia and learning in starlings is the strong and positive correlation between individuals' competitive rank and their learning performance in the absence of groupmates, in all three starling groups studied. To our knowledge, this is the first study reporting competitively high-ranking animals mastering an individual learning skill faster than lower-ranking groupmates outside the context of the group, although Barnard \& Luo (2002) reported a similar finding for pairs of mice.

Humphrey (1976) hypothesized that intellectual prowess' would be correlated with 'social success'. However, the few studies that have addressed this hypothesis in gregarious species by testing individuals outside the wholegroup context suggested that subordinate and dominant rhesus macaques have similar capacities to learn (Drea \& Wallen 1999) and that subordinate longtailed macaques are superior learners (Bunnell \& Perkins 1980; Bunnell et al. 1980). Furthermore, in the latter studies, changes in individuals' social ranks were frequent and followed by changes in performance on the individual learning task; a drop in an animal's relative rank was accompanied by improved performance relative to the rest of the group, and a rise by poorer performance, leading the authors to assert that there did not seem to exist an inherent negative relationship between some hypothetical generalized learning ability and social rank' (Bunnell \& Perkins 1980, page 522). However, methodological factors might have been of paramount importance in Bunnell et al.'s experiments, as rank was determined at the same time as the individual learning tests were carried out. An animal's maintenance of high rank might have been complicated by the continual removal of individuals from the group for learning test sessions and their subsequent return. Bunnell et al. (1980) proposed that these removals created chronic social pressure for dominants that may have carried over to the individual testing situation in the laboratory and disrupted their performance.

Insights into the mechanisms underlying the social rank-learning correlation may be acquired by altering group membership and thus individuals' positions in the competitive rank order. (Such a method may be preferable to rearing animals in isolation and then placing them in a group, which would eliminate any effect of group living on learning performance but carries the disadvantages of isolation rearing.) If competitive rank affects performance on the individual learning task, changes in relative rank should be accompanied by changes in learning performance. Acquisition of dominance status has already been found to affect maze learning in mice (Barnard \& Luo 2002). In contrast, if individual learning performance of the starlings does not change with changes in group composition, it may be used to predict competitive ranks within the new groups. This would support the 'prior attributes' hypothesis (Chase et al. 2002), one of the 
Table 2. Spearman rank correlation coefficients between social rank orders and individual variables

\begin{tabular}{|c|c|c|c|c|}
\hline \multirow[b]{2}{*}{ Rank order } & \multirow[b]{2}{*}{ Individual variable } & \multicolumn{3}{|c|}{ Group } \\
\hline & & 1 & 2 & 3 \\
\hline Agonistic & $\begin{array}{l}\text { Latency to feed in } \\
\text { novel environment }\end{array}$ & $0.30(0.62)$ & $0.80(0.10)$ & $-0.40(0.51)$ \\
\hline Competitive & $\begin{array}{l}\text { Latency to feed in } \\
\text { novel environment }\end{array}$ & $0.00(1.00)$ & $0.50(0.39)$ & $1.00\left(<0.01^{* *}\right)$ \\
\hline Agonistic & Object neophobia & $0.30(0.62)$ & $0.90\left(0.04^{\star}\right)$ & $-0.10(0.87)$ \\
\hline Competitive & Object neophobia & $0.20(0.75)$ & $0.20(0.75)$ & $0.20(0.75)$ \\
\hline Agonistic & Individual learning & $-0.90\left(0.04^{*}\right)$ & $-0.20(0.75)$ & $0.00(1.00)$ \\
\hline Competitive & Individual learning & $0.90\left(0.04^{*}\right)$ & $0.90\left(0.04^{\star}\right)$ & $0.90\left(0.04^{*}\right)$ \\
\hline
\end{tabular}

$P$ values are in parentheses. The same pattern of results is found if object neophobia is calculated as the difference in time to feed between trials 2 and 3 rather than with a residual measure, except that the agonistic rank-object neophobia correlation in group 2 becomes weaker $\left(r_{\mathrm{S}}=0.60, N=5, P=0.29\right.$ ). The two methods of calculating object neophobia correlate strongly (Pearson correlation object neophobia residuals versus difference in time to feed: $\left.r_{13}=0.85, P<0.001\right)$. Correlation statistically significant after correction for familywise error rate is shown in bold. $P$ values below $\alpha^{*}=0.017$ are considered significant.

${ }^{*} P<0.05 ;{ }^{* *} P<0.01$.

explanations proposed by Wilson et al. (1994) for the relation between boldness and dominance. (See Chase 1980 for discussion of hierarchy formation in small groups.) The correlation coefficient of 0.9 between individual learning performance and competitive rank that we obtained in this study meets Chase's (1974) stringent mathematical condition for linear dominance hierarchies to be determined by individuals' characteristics. This might suggest learning performance is a causal determinant of competitive rank, as suggested by Humphrey's (1976) social intelligence hypothesis. Alternatively, dominance interactions within the group may carry over to affect individual performance when tested in isolation. A third possibility is that rank and individual learning performance are not directly related, but are mediated by a third variable, such as motivation to acquire desired resources. Clearly, further studies are necessary to determine which variable is the cause and which the effect in the strong and positive association between social rank and individual learning performance reported here in starlings.

Our second hypothesis concerning the lack of an association between social rank and neophobia when tested in individuals in the absence of their groupmates was also supported, for both agonistic and competitive social rank orders versus both object neophobia and latency to feed in a novel environment. Furthermore, in each starling group, no significant relation was found between competitive rank order (based on monopolization of limited resources) and agonistic rank order (based on displacements). Although the small sample size in the present study warrants caution in interpreting these negative findings, a similar low correlation between agonistic and competitive rank orders has been reported for a wide variety of other species such as cats, rats, mice, frogs and monkeys (Syme 1974), and more recently in bonobos, Pan paniscus (Vervaecke et al. 2000) and domestic fowl (Cloutier et al. 2004). In contrast, agonistic and competitive rank orders were shown to agree in other studies of some of the aforementioned and other species (e.g. Richards 1974; Syme et al. 1974; Vervaecke et al. 1999; Wittig \& Boesch 2003). Whether different types of social rank orders agree with each other thus seems to depend on the particular species under study and the specific methods of assessment. The scarcity of studies adopting a multidimensional approach to dominance makes it difficult to draw any general conclusions. Furthermore, various researchers have noted problems with the concept of dominance, both operational, when rank order is assumed to govern the social interactions within a group (Syme 1974), and theoretical, when attempts are made to analyse the relevant agonistic interactions data in a satisfactory

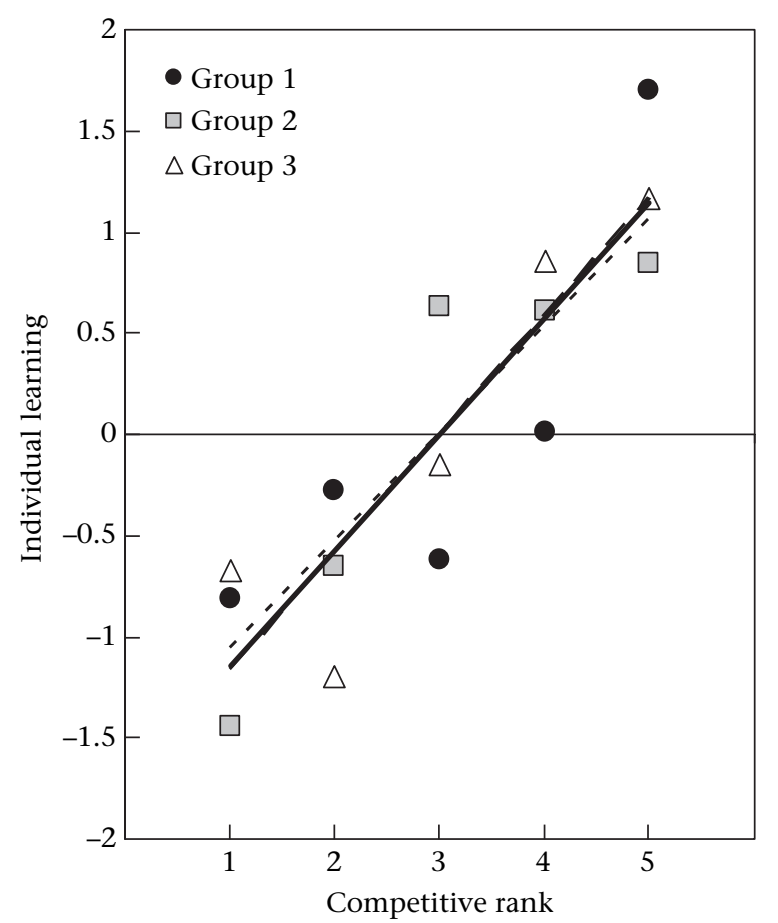

Figure 2. The relation between individual learning performance ( $Z$ scores log (cumulative number of trials to pass level 4$)$ ) and competitive rank for starling groups 1,2 and 3 . Each datum represents one bird. - - -: Group 1: $Y=0.47 X-1.82, R^{2}=0.65$; - - group 2: $Y=0.58 X-1.35, R^{2}=0.85 ;-$ : group 3 : $Y=0.57 X-1.72, R^{2}=0.82$. Note that the $R^{2}$ values relate to the regression lines and therefore do not match the Spearman rank correlation coefficients in Table 2. 
way (de Vries 1998; Gammell et al. 2003; Langbein \& Puppe 2004). Unfortunately, these concerns appear to be rarely taken into account in studies that adopt dominance rank as an explanatory variable. The discordance between agonistic and competitive rank orders observed here in starlings, and reported elsewhere for other species, underlines the importance of both defining exactly the specific measurements taken and analysing relations with other variables for each dominance measure separately, rather than treating dominance as a one-dimensional concept.

Latencies to feed near a variety of novel objects were consistent within individuals, but did not correlate with individuals' latency to feed in a novel environment. Thus both measures were in the foraging context, where context is 'a functional behavioural category', but in different situations (Sih et al. 2004). The low power of this analysis means that a significant correlation might have been found with more starlings at our disposal. None the less, these results, combined with previous findings (Coleman \& Wilson 1998), suggest that novelty responses may not be a simple unitary trait that is consistent across situations (Greenberg 2003). Our finding of consistent object neophobia suggests this can be considered a temperament trait, as in other bird species (Drent et al. 2003).

Object neophobia did not correlate with individual learning performance, which implies that skill at solving the foraging task was not an artefact of individual differences in neophobia to the task. In apparent contrast, object neophobia did correlate with flexibility in problemsolving attempts in five opportunistic avian species on Barbados (Webster \& Lefebvre 2001). Furthermore, both feral pigeons, Columba livia, and Zenaida doves, Zenaida aurita, that were slow to feed from a novel apparatus were also slow at learning to open it (Seferta et al. 2001). This discrepancy may reflect methodological differences. In contrast to our experiments, the test subjects in the studies by Seferta et al. (2001) and Webster \& Lefebvre (2001) were never habituated to the foraging task apparatus to the extent that they fed from it within their normal, or 'control', latency to feed. Indeed, the research literature supports Greenberg's (2003) remark that animals shying away from unfamiliar situations, as reflected by, for example, their object neophobia, are unlikely to assess the costs and benefits of a novel foraging opportunity such as finding the solution to a novel foraging task. Thorough familiarization with the task to be solved in our study before assessment of individuals' learning performance, with the aim of minimizing interindividual differences in object neophobia as a confounding variable, may explain the discrepancy with previously reported findings.

Latency to feed in a novel environment did correlate with individual learning performance such that the starlings least hesitant to feed were also the fastest learners. At first glance, this is surprising as the starlings had habituated to the test cage (through establishment of a control latency to feed) before they were presented with the individual learning task. Powell (1974) noted both considerable variation in surveillance scan frequency between individual foraging starlings and increases in surveillance behaviour as group size was decreased. Scanning tendencies may plausibly correlate with latency to feed in a novel environment, as both behavioural variables seem to reflect a certain 'alertness' to the wider environment. Solution of the individual learning task in our study required the test subject to engage repeatedly in exploratory bouts of the apparatus, presumably hampering surveillance (although see Fernández-Juricic et al. 2005). If it is assumed that (1) problem solving and vigilance cannot be performed simultaneously (reminiscent of Giraldeau \& Caraco's 2000 assumptions for the adoption of either a 'producer' or a 'scrounger' strategy), and that (2) individuals' vigilance is positively correlated with their latency to feed in a novel environment, it follows that individuals less hesitant in a novel environment would spend less time performing vigilant behaviour and thus have more time available to engage in problem solving.

In summary, our experiments on three groups of wildcaught starlings suggest: (1) fast individual learners occupied high competitive ranks; (2) neophobia was not related to social rank outside the context of the group; (3) fast individual learners were fast to feed in a novel environment; and (4) social ranks and individual neophobia were dependent on the specific methods of assessment. These variables necessitate a multidimensional approach when adopted as explanatory factors.

\section{Acknowledgments}

We thank Kate Smith and Vincent Janik for help with capturing and releasing birds, Isobel Maynard for caring for the starlings, Han de Vries for statistical advice and the members of the Behavioural Discussion Group at the University of St Andrews for helpful suggestions. We are grateful to the anonymous referees and the editor for their valuable comments. N.J.B. gratefully acknowledges the Lucie Burgers Foundation for Comparative Behaviour Research, Arnhem, The Netherlands for financial support.

\section{References}

Barnard, C. J. \& Luo, N. 2002. Acquisition of dominance status affects maze learning in mice. Behavioural Processes, 60, 53-59.

Bateson, M. \& Kacelnik, A. 1995. Accuracy of memory for amount in the foraging starling, Sturnus vulgaris. Animal Behaviour, 50, 431-443.

di Bitetti, M. S. \& Janson, C. H. 2001. Social foraging and the finder's share in capuchin monkeys, Cebus apella. Animal Behaviour, 62, 47-56.

Bugnyar, T. \& Kotrschal, K. 2004. Leading a conspecific away from food in ravens (Corvus corax)? Animal Cognition, 7, 69-76.

Bunnell, B. N. \& Perkins, M. N. 1980. Performance correlates of social behavior and organization: social rank and complex problem solving in crab-eating macaques (M. fascicularis). Primates, 21, 515-523.

Bunnell, B. N., Gore, W. T. \& Perkins, M. N. 1980. Performance correlates of social behavior and organization: social rank and reversal learning in crab-eating macaques (M. fascicularis). Primates, 21, 376-388.

Byrne, R. W. \& Whiten, A. 1988. Machiavellian Intelligence: Social Expertise and the Evolution of Intellect in Monkeys, Apes and Humans. Oxford: Oxford University Press.

Cambefort, J. P. 1981. A comparative study of culturally transmitted patterns of feeding habits in the chacma baboon Papio ursinus and 
the vervet monkey Cercopithecus aethiops. Folia Primatologica, 36, 243-263.

Campbell, F. M., Heyes, C. M. \& Goldsmith, A. R. 1999. Stimulus learning and response learning by observation in the European starling, in a two-object/two-action test. Animal Behaviour, 58, 151-158.

Carlier, P. \& Lefebvre, L. 1996. Differences in individual learning between group-foraging and territorial Zenaida doves. Behaviour, 133, 1197-1207.

Chase, I. D. 1974. Models of hierarchy formation in animal societies. Behavioral Science, 19, 374-382.

Chase, I. D. 1980. Social process and hierarchy formation in small groups: a comparative perspective. American Sociological Review, 45, 905-924.

Chase, I. D. 1982. Behavioral sequences during dominance hierarchy formation in chickens. Science, 216, 439-440.

Chase, I. D., Tovey, C., Spangler-Martin, D. \& Manfredonia, M. 2002. Individual differences versus social dynamics in the formation of animal dominance hierarchies. Proceedings of the National Academy of Sciences, U.S.A., 99, 5744-5749.

Cloutier, S., Newberry, R. C. \& Honda, K. 2004. Comparison of social ranks based on worm-running and aggressive behaviour in young domestic fowl. Behavioural Processes, 65, 79-86.

Cohen, J. 1988. Statistical Power Analysis for the Behavioral Sciences. Hillsdale, New Jersey: L. Erlbaum.

Coleman, K. \& Wilson, D. S. 1998. Shyness and boldness in pumpkinseed sunfish: individual differences are context-specific. Animal Behaviour, 56, 927-936.

Drea, C. M. \& Wallen, K. 1999. Low-status monkeys 'play dumb' when learning in mixed social groups. Proceedings of the National Academy of Sciences, U.S.A., 96, 12965-12969.

Drent, P., Van Oers, K. \& Van Noordwijk, A. J. 2003. Realised heritability of personalities in the great tit (Parus major). Proceedings of the Royal Society of London, Series B, 270, 45-51.

Dunbar, R. I. M. 2003. The social brain: mind, language, and society in evolutionary perspective. Annual Review of Anthropology, 32, 163-181.

Fawcett, T. W., Skinner, A. M. J. \& Goldsmith, A. R. 2002. A test of imitative learning in starlings using a two-action method with an enhanced ghost control. Animal Behaviour, 64, 547-556.

Feare, C. 1984. The Starling. Oxford: Oxford University Press.

Fernández-Juricic, E., Smith, R. \& Kacelnik, A. 2005. Increasing the costs of conspecific scanning in socially foraging starlings affects vigilance and foraging behaviour. Animal Behaviour, 69, 73-81.

Gammell, M. P., de Vries, H., Jennings, D. J., Carlin, C. M. \& Hayden, T. J. 2003. David's score: a more appropriate dominance ranking method than Clutton-Brock et al.'s index. Animal Behaviour, 66, 601-605.

Giraldeau, L.-A. \& Caraco, T. 2000. Social Foraging Theory. Princeton, New Jersey: Princeton University Press.

Greenberg, R. 1983. The role of neophobia in determining the degree of foraging specialization in some migrant warblers. American Naturalist, 122, 444-453.

Greenberg, R. 1984. Differences in feeding neophobia in the tropical migrant wood warblers Dendroica castanea and $D$. pensylvanica. Journal of Comparative Psychology, 98, 131-136.

Greenberg, R. 2003. The role of neophobia and neophilia in the development of innovative behaviour of birds. In: Animal Innovation (Ed. by S. M. Reader \& K. N. Laland), pp. 175-196. Oxford: Oxford University Press.

Humphrey, N. K. 1976. The social function of intellect. In: Growing Points in Ethology (Ed. by P. P. G. Bateson \& R. A. Hinde), pp. 303317. Cambridge: Cambridge University Press.
Kacelnik, A. \& Marsh, B. 2002. Cost can increase preference in starlings. Animal Behaviour, 63, 245-250.

Katzir, G. 1982. Relationships between social structure and response to novelty in captive jackdaws, Corvus monedula L., I. Response to novel space. Behaviour, 81, 231-264.

King, M. G. 1965. Disruptions in the pecking order of cockerels concomitant with degrees of accessibility to feed. Animal Behaviour, 13, 504-506.

Kummer, H. \& Goodall, J. 1985. Conditions of innovative behaviour in primates. Philosophical Transactions of the Royal Society of London, Series B, 308, 203-214.

Laland, K. N. \& Reader, S. M. 1999. Foraging innovation in the guppy. Animal Behaviour, 57, 331-340.

Langbein, J. \& Puppe, B. 2004. Analysing dominance relationships by sociometric methods: a plea for a more standardised and precise approach in farm animals. Applied Animal Behaviour Science, 87, 293-315.

Lefebvre, L. \& Giraldeau, L.-A. 1996. Is social learning an adaptive specialization? In: Social Learning in Animals: the Roots of Culture (Ed. by C. M. Heyes \& B. G. Galef Jr), pp. 107-128. New York: Academic Press.

Lehner, P. N. 1996. Handbook of Ethological Methods. Cambridge: Cambridge University Press.

Martin, P. R. \& Bateson, P. 1993. Measuring Behaviour: An Introductory Guide. 2nd edn. Cambridge: Cambridge University Press.

Nicol, C. J. \& Pope, S. J. 1999. The effects of demonstrator social status and prior foraging success on social learning in laying hens. Animal Behaviour, 57, 163-171.

Powell, G. V. N. 1974. Experimental analysis of the social value of flocking by starlings (Sturnus vulgaris) in relation to predation and foraging. Animal Behaviour, 22, 501-505.

Reader, S. M. \& Laland, K. N. 2001. Primate innovation: sex, age and social rank differences. International Journal of Primatology, 22, 787-805.

Reader, S. M. \& Laland, K. N. 2002. Social intelligence, innovation and enhanced brain size in primates. Proceedings of the National Academy of Sciences, U.S.A., 99, 4436-4441.

Reader, S. M. \& Laland, K. N. 2003. Animal innovation: an introduction. In: Animal Innovation (Ed. by S. M. Reader \& K. N. Laland), pp. 3-35. Oxford: Oxford University Press.

Rice, W. E. 1989. Analyzing tables of statistical tests. Evolution, 43, 223-225.

Richards, S. M. 1974. The concept of dominance and methods of assessment. Animal Behaviour, 22, 914-930.

Seferta, A., Guay, P.-J., Marzinotto, E. \& Lefebvre, L. 2001. Learning differences between feral pigeons and Zenaida doves: the role of neophobia and human proximity. Ethology, 107, 281-293.

Seyfarth, R. M. \& Cheney, D. L. 2002. What are big brains for? Proceedings of the National Academy of Sciences, U.S.A., 99, 4141-4142.

Sih, A., Bell, A. \& Johnson, J. C. 2004. Behavioral syndromes: an ecological and evolutionary overview. Trends in Ecology and Evolution, 19, 372-378.

Sokal, R. R. \& Rohlf, F. J. 1998. Biometry: the Principles and Practice of Statistics in Biological Research. New York: W.H. Freeman.

Stahl, J., Tolsma, P. H., Loonen, M. J. J. E. \& Drent, R. H. 2001. Subordinates explore but dominants profit: resource competition in high Arctic barnacle goose flocks. Animal Behaviour, 61, 257-264.

Summers, R. W., Westlake, G. E. \& Feare, C. J. 1987. Differences in the ages, sexes and physical condition of starlings Sturnus vulgaris at the centre and periphery of roosts. Ibis, 129, 96-102.

Swaddle, J. P. \& Witter, M. S. 1994. Food, feathers and fluctuating asymmetries. Proceedings of the Royal Society of London, Series B, 255, 147-152. 
Swaddle, J. P. \& Witter, M. S. 1995. Chest plumage, dominance and fluctuating asymmetry in female starlings. Proceedings of the Royal Society of London, Series B, 260, 219-223.

Syme, G. J. 1974. Competitive orders as measures of social dominance. Animal Behaviour, 22, 931-940.

Syme, G. J., Pollard, J. S., Syme, L. A. \& Reid, R. M. 1974. An analysis of the limited access measure of social dominance in rats. Animal Behaviour, 22, 486-500.

Tebbich, S., Taborsky, M. \& Winkler, H. 1996. Social manipulation causes cooperation in keas. Animal Behaviour, 52, 1-10.

Templeton, J. J. 1998. Learning from others' mistakes: a paradox revisited. Animal Behaviour, 55, 79-85.

Templeton, J. J. \& Giraldeau, L.-A. 1995. Public information cues affect the scrounging decisions of starlings. Animal Behaviour, 49, 1617-1626.

Templeton, J. J., Kamil, A. C. \& Balda, R. P. 1999. Sociality and social learning in two species of corvids: the pinyon jay (Gymnorhinus cyanocephalus) and the Clark's nutcracker (Nucifraga columbiana). Journal of Comparative Psychology, 113, 450-455.

Vervaecke, H., de Vries, H. \& van Elsacker, L. 1999. An experimental evaluation of the consistency of competitive ability and agonistic dominance in different social contexts in captive bonobos. Behaviour, 136, 423-442.
Vervaecke, H., de Vries, H. \& van Elsacker, L. 2000. Dominance and its behavioral measures in a captive group of bonobos (Pan paniscus). International Journal of Primatology, 21, 47-68.

de Vries, H. 1998. Finding a dominance order most consistent with a linear hierarchy: a new procedure and review. Animal Behaviour, 55, 827-843.

de Vries, H., Stevens, J. M. G. \& Vervaecke, H. 2006. Measuring and testing the steepness of dominance hierarchies. Animal Behaviour, 71, 585-592.

Webster, S. J. \& Lefebvre, L. 2001. Problem solving and neophobia in a columbiform-passeriform assemblage in Barbados. Animal Behaviour, 62, 23-32.

Wilson, D. S., Clark, A. B., Coleman, K. \& Dearstyne, T. 1994. Shyness and boldness in humans and other animals. Trends in Ecology and Evolution, 9, 442-446.

Witter, M. S. \& Goldsmith, A. R. 1997. Social stimulation and regulation of body mass in female starlings. Animal Behaviour, 54, 279-287.

Witter, M. S. \& Swaddle, J. P. 1994. Fluctuating asymmetries, competition and dominance. Proceedings of the Royal Society of London, Series B, 256, 299-303.

Wittig, R. M. \& Boesch, C. 2003. Food competition and linear dominance hierarchy among female chimpanzees of the Tai National Park. International Journal of Primatology, 24, 847-867. 